\title{
STUDI PEMILIHAN JENIS ALAT ANGKUT \\ BAHAN BAKAR MINYAK WILAYAH KEPULAUAN
}

\author{
Edwin Matatula \\ e-mail: edwin.matatula@gmail.com \\ Program Studi Teknik Perkapalan Fakultas Teknik - Unpatti
}

\begin{abstract}
ABSTRAK
Supplying fuel oil to the outermost and foremost islands, faced a relatively long distribution chain, especially in the most recent network to consumers on the island, many economic and technical problems. Economically, the people in the outermost islands, the foremost, have small-scale economic dynamics which causes relatively little oil fuel consumption. While technically, infrastructure support in supporting the supply process is very minimal. The fleet of ships as the main means of transporting fuel oil are people's vessels which are designed not specifically to transport liquid cargo. These vessels have relatively small types and dimensions, with very minimal safety equipment. The unavailability of ship dock facilities for loading and unloading so that the loading and unloading process is adequate on the island. Another thing is the geographical conditions of the scattered region and the influence of the weather, high sea waves in certain seasons which hinder transport activities. These constraints later caused the process of distribution of fuel oil to not run smoothly and there was a scarcity of inventory, even a vacancy occurred and triggered a surge in prices.

The selection of fuel transportation equipment between the Tug-barge, Self Propelled Oil Barge and Tanker using the Analytic Hierarchy Process (AHP) approach, produces tug-barge as the main choice. Furthermore, operational planning is carried out by considering the demand quantity, shipping distance, operating conditions and regional characteristics. Pusher-Barge, which is offered in the Central Maluku Lease Islands, has a relatively high investment value, but there is a significant savings in the operating cost component of 54\%, $78 \%$ sailing cost and $45,18 \%$ decrease in total transport costs per year current system.
\end{abstract}

Kay Word: Islands Region, Distribution Model, Tug-Barge, AHP

\section{PENDAHULUAN}

Bahan bakar merupakan salah satu komoditas energi yang vital dalam menunjang berbagai aktifitas ekonomi masyarakat. Apapun tingkat ekonomi masyarakat selalu membutuhkan bahan bakar untuk aktifitasnya, mulai aktifitas rumah tangga, alat transportasi maupun untuk kepentingan industri baik skala kecil sampai dengan yang skala besar. Ada hubungan yang signifikan antara peningkatan ekonomi dan semakin meningkatknya jumlah penduduk di suatu wilayah dengan kebutuhan energi dan sebaliknya. Kebutuhan bahan bakar yang diikuti dengan upaya penyediaan yang baik akan menunjang dan memperlancar kegiatan-kegiatan ekonomi, yang pada gilirannya akan meningkatkan taraf hidup dan kesejahteraan masyarakat.

Salah satu jenis bahan bakar yang banyak dikonsumsi saat ini dan masih menjadi sumber energi utama adalah bahan bakar minyak, dimana untuk konsumsi nasional berada pada kisaran $85-90 \%$ dibandingkan bahan bakar gas dan non-BBM. ( Statistik Minyak Bumi - ESDM, 2015 ) Rantai distribusi bahan bakar minyak secara nasional sebagaimana terlihat pada Gambar 1.1, dimulai dari pusat pengilangan, kemudian didistribusikan ke terminal-terminal penampungan yang ada pada wilayah tertentu dengan jangkauan pelayanan kadang meliputi beberapa wilayah propinsi.

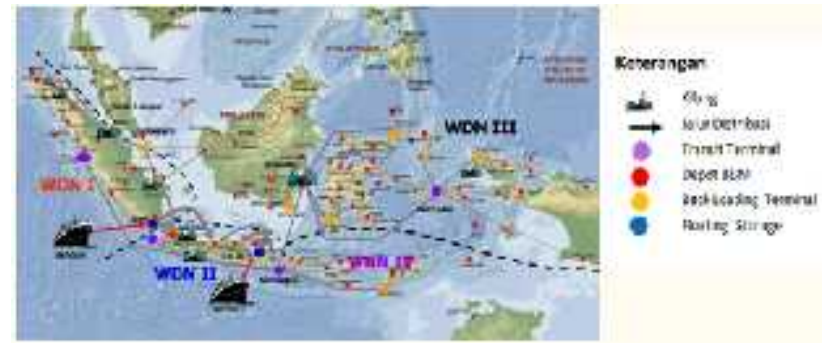

Gambar 1.1. Jaringan Distribusi BBM Nasional

Dari terminal penampungan (terminal transit), selanjutnya dilakukan pendistribusian ke depot-depot yang ada pada lingkup wilayah yang lebih kecil sesuai dengan kuantitas atau kuota BBM yang dibutuhkan. Proses distribusi bahan bakar minyak paling akhir yakni dari depot ke lembaga penyalur resmi yakni Agen Premium Minyak dan Solar (APMS), Stasiun Pengisian Bahan Bakar Umum (SPBU), dan Agen Minyak Tanah (AMT). Agenagen resmi ini kemudian yang menjadi titik layanan untuk memenuhi kebutuhan masyarakat sebagai konsumen akhir. Secara skematik, sebagaimana terlihat pada Gambar 2.

Dalam konteks wilayah kepulauan, lokasi depot, agen dan konsumen akhir tidak selalu berada pada teritorial atau pulau yang sama. Kondisi ini memerlukan proses pendistribusian lanjutan kepada konsumen yang ada di pulau-pulau lainnya. 


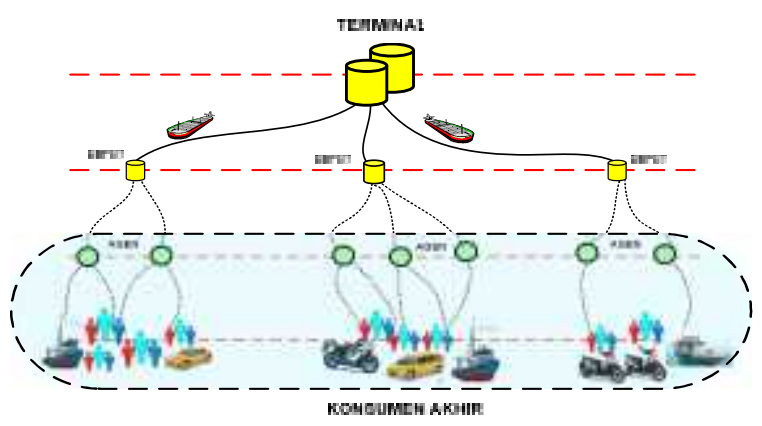

Gambar 1.2. Level Distribusi Dari Terminal ke Konsumen Akhir

Pada level penyediaan ini, pengangkutan bahan bakar minyak dilayani oleh armada kapal rakyat yang secara teknis dapat dikatakan kurang layak dan rentan terhadap kondisi cuaca buruk ( gelombang tinggi ).

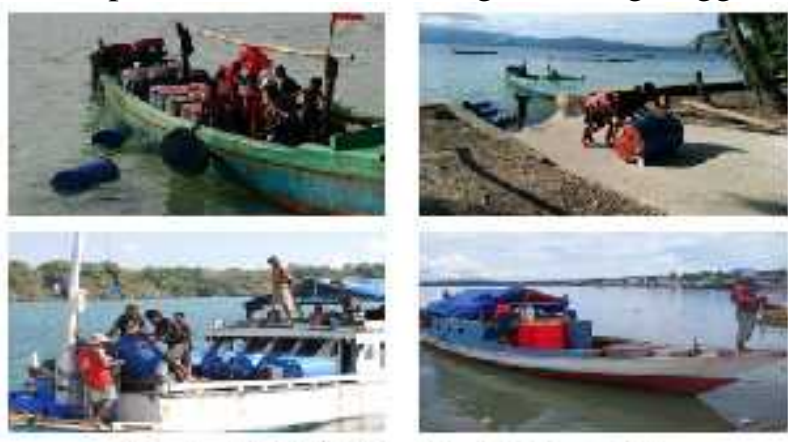

Lianbar 1.x. 'Tipikal Angkatan IIIM Anrar Bulau

Kapal-kapal ini umumnya berkonstruksi kayu dan kapal tidak di desain secara khusus untuk mengangkut muatan cair. Dari sisi penanganan muatan, bahan bakar minyak di kemas dalam drum yang kemudian diletakan di atas geladak atau di lantai kapal. Selama pelayaran kemasan drum ini umumnya tidak dilengkapi atau dipasang dengan sistim pengamanan muatan bahan (lashing ). Kondisi ini sangat berbahaya karena bisa terjadi pergeseran titik berat muatan dan mengancam keselamatan pelayaran, apabila dalam kondisi cuaca buruk.

Minimnya dukungan infrastruktur, gangguan cuaca dan kondisi geografis wilayah sebagaimana digambarkan diatas, menyebabkan sering terganggunya sistim distribusi bahan bakar minyak di wilayah kepulauan. Hal ini kemudian menimbulkan lonjakan harga bahan bakar, bahkan terjadi kelangkaan persediaan yang berakibat terganggunya aktifitas masyarakat di wilayah pulau.

Penelitian yang diusulkan ini pada dasarnya akan merumuskan bagaimana tipe dan jenis kapal angkutan bahan bakar minyak untuk wilayah kepulauan.

Berdasarkan rumusan masalah diatas, maka dapatlah beberapa masalah dalam penelitian ini, sebagai berikut :

1. Bagaimana tipe dan jenis kapal pengangkut bahan bakar minyak di wilayah kepulauan saat ini.
2. Bagaimana pola operasi pengangkutan bahan bakar minyak saat ini.

Penelitian ini dilakukan dengan wilayah studi di daerah Maluku Tengah, khususnya di Pulau Nusalaut, Pulau Saparua dan Pulau Haruku. adalah:

Tujuan yang ingin dicapai penelitian ini

1. Menentukan tipe dan jenis kapal yang sesuai dengan karakteristik wilayah.

2. Menentukan pola penyediaan bahan bakar minyak untuk menjamin ketersediaan bahan bakar minyak sesuai tingkat kebutuhan masyarakat di pulau.

\section{KAJIAN TEORI DAN METODE}

\subsection{Pengertian Logistik}

Logistik adalah proses perencanaan, penerapan dan pengawasan secara efisien dan efektif terhadap distribusi dan penyimpanan material pada proses inventory, penanganan pelayanan komoditi dan juga arus informasi dari asal ke tujuan sesuai dengan permintaan konsumen, (John J. Coyle ,1996). Manajemen rantai suplai adalah serangkaian pendekatan digunakan untuk efisien mengintegrasikan pemasok, pabrik, gudang, dan toko, sehingga barang diproduksi dan didistribusikan pada kuantitas yang tepat, ke lokasi yang tepat, dan pada saat yang tepat, untuk meminimalkan biaya sistem yang luas sedangkan tingkat pelayanan harus memuaskan kebutuhan, ( Lazaros G.Papageorgiou, 2009 ). Selanjutnya dikatakan ; "Manajemen rantai suplai merupakan koordinasi produksi, persediaan, lokasi, dan transportasi di antara para elemen-elemen dalam supply chain untuk mencapai suatu interaksi yang baik, responsif dan efisiensi untuk pasar yang dilayani".

Dalam industri, distribusi diartikan sebagai seluruh aktifitas bisnis yaitu proses perpindahan barang/komoditi dari sentra produksi ke pasar/konsumen yang didalamnya terdapat aktifitas pabrikasi, inventory, cargo handling and pengepakan, dokumentasi, dan pelayanan purna jual. (Frank H. Woodward,1980). Transportasi mempunyai peranan penting bagi industri karena produsen mempunyai kepentingan agar barangnya diangkut sampai kepada konsumen tepat waktu, tepat pada tempat yang ditentukan, dan barang dalam kondisi baik. Dengan demikian, maka aktifitas transport merupakan bagian dari pengertian distribusi.

Hal yang sama ditegaskan oleh John. J. Coyle, ( 1996) , bahwa pada prinsipnya aktifitas logistik memiliki fungsi waktu dan tempat. Logistik menyediakan fungsi tempat dengan memindahkan barang/komoditi dari titik produksi ke titik surplus di mana permintaan ada. Logistik memperluas batas-batas fisik daerah 
pasar, sehingga menambah nilai ekonomi untuk barang. Logistik menciptakan utilitas tempat terutama melalui transportasi. Nilai waktu mengandung arti bahwa barang dan jasa akan tersedia di mana konsumen membutuhkan mereka, tetapi mereka juga harus ada pada saat pelanggan membutuhkan. Nilai tambah ekonomi terhadap barang atau jasa oleh karena itu pada titik permintaan pada waktu tertentu. Logistik menciptakan utilitas waktu dengan menjaga persediaan yang tepat dan lokasi strategis barang dan jasa.

\subsection{Permintaan dan Penawaran Transportasi Laut}

Penentuan kebutuhan akan jasa transportasi secara menyeluruh sekarang dan masa yang akan datang merupakan langkah awal yang penting dan sangat berpengaruh bagi optimasi penjadwalan pengoperasian dan pengadaan armada kapal. Kebutuhan akan jasa transportasi laut berupa ketersediaan infrastruktur transportasi akan dianalisa melalui pemodelan permintaan ( demand) dan penawaran (supply). Pemodelan banyak dimanfaatkan secara luas untuk mempelajari permasalahan yang kompleks. Model yang baik akan dapat mewakili permasalahan secara benar dan sederhana tetapi menyeluruh, sehingga karakteristik dan perilaku permasalahan dari objek yang dipelajari dapat diidentifikasi dan dikontrol dengan mudah. Pengontrolan adalah pengidentifikasian dari sistim yang dipelajari, yang meliputi komponen, perilaku operasional, batas-batas permasalahan dan lingkungan yang melingkupi secara benar dan akurat dalam bentuk suatu model. Solusi dari pemodelan permintaan dan penawaran adalah terjadinya keseimbangan ( equalibrium ) yang merupakan kondisi ideal untuk menghindari over supply dan inefficient

Tujuan dasar perencanaan transportasi adalah memperkirakan jumlah serta lokasi kebutuhan akan transportasi (misalnya menentukan total pergerakan, baik untuk angkutan umum maupun pribadi) pada masa mendatang atau pada tahun rencana yang akan digunakan untuk berbagai kebijakan investasi perencanaan transportasi.

Perencanaan kebutuhan kapal untuk transportasi antar pulau membutuhkan data-data sebagai berikut, ( Erichsen,1989) :

\section{- Besaran, fluktuasi, estimasi durasi dan arus alami dari barang dan penumpang.}

Informasi mengenai potensi arus barang dan penumpang lengkap dengan proyeksi masa depan pada trayek yang direncanakan perlu diketahui agar dapat ditentukan kelayakan pengadaan kapal serta dimensi dan jenis kapal. Kapal yang akan dioperasikan harus memiliki nilai ekonomis berupa pendapatan yang akan digunakan untuk membiayai biaya investasi, biaya operasional dan keuntungan bagi operator untuk menjamin kelangsungan kapal dan operator.

\section{* Lokasi dan jarak antara pelabuhan}

Penentuan lokasi dan jarak antar pelabuhan diperlukan untuk aspek ekonomis yaitu penentuan tarif terhadap barang dan jasa dan aspek teknis yaitu penentuan kapasitas consumable kapal yang berujung pada dimensi dan kapasitas total kapal.

\section{* Jalur pelayaran dan panduan navigasi}

Jalur pelayaran dan kondisi navigasi menentukan karasteristik bangunan kapal dan perlengkapan kapal, termasuk perlengkapan keselamatan. Untuk kapal dengan jalur pelayaran yang ramai atau rawan kecelakaan tentu akan berbeda dengan kapal yang beroperasi pada jalur pelayaran yang sepi. Demikian juga dengan kondisi alam sekitar jalur pelayaran.

\section{* Keandalan dari Pelayanan Pelabuhan}

Pelayanan yang diberikan pelabuhan pada kapal mempengaruhi waktu sandar dan operasional kapal di pelabuhan. Sehingga perencanaan kapal perlu mempertimbangkan karakteristik pelayanan pelabuhan yang akan disinggahi agar kapal dapat memberi kemudahan bagi pelayanan pelabuhan.

\section{* Fasilitas Pelabuhan}

Fasilitas yang dimiliki pelabuhan sangat berpengaruh terhadap perencanaan perlengkapan kapal, seperti penyediaan alat untuk material handling derek atau crane, dan sebagainya. Atau bisa berpengaruh juga terhadap desain kapal secara keseluruhan.

\subsection{Analisis Hierarki Proses ( AHP )}

AHP merupakan salah satu alat bantu (proses) dalam pengambilan keputusan yang dikembangkan oleh Thomas L. Saaty pada tahun 70-an. Prosedur ini begitu powerfull sehingga sudah diaplikasikan secara luas dalam pengambilan keputusan yang penting. Penggunaan AHP bukan hanya untuk institusi pemerintahan atau swasta namun juga dapat diaplikasikan untuk keperluan individu terutama untuk penelitian-penelitian yang berkaitan dengan kebijakan atau perumusan strategi prioritas. AHP dapat diandalkan, karena dalam AHP suatu prioritas disusun dari berbagai pilihan yang dapat berupa kriteria yang sebelumnya telah didekomposisi terlebih dahulu, sehingga penetapan prioritas didasarkan pada suatu proses yang terstruktur (hierarki) dan masuk akal. Jadi pada intinya AHP membantu memecahkan persoalan yang kompleks dengan menyusun suatu hirarki kriteria, dinilai secara subjektif oleh pihak yang berkepentingan lalu 
menarik berbagai pertimbangan guna mengembangkan bobot atau prioritas.

\subsection{Prosedur AHP}

Terdapat tiga prinsip utama dalam pemecahan masalah dalam AHP menurut Saaty, yaitu: Decompositiot, Comparative Judgement, dan Logical Concistency. Secara garis besar prosedur AHP meliputi tahapan sebagai berikut:

a) Dekomposisi masalah;

b) Penilaian/pembobotan untuk membandingkan elemen-elemen;

c) Penyusunan matriks dan Uji consistensi;

d) Penetapan prioritas pada masing-masing hierarki;

e) Sistesis dari prioritas; dan

f) Pengambilan/penetapan keputusan.

\section{a. Dekomposisi Masalah / Menyusun Hierarki}

Dekomposisi masalah adalah langkah dimana suatu tujuan (goal) yang telah ditetapkan selanjutnya diuraikan secara sistematis kedalam struktur yang menyusun rangkaian sistem hingga tujuan dapat dicapai secara rasional. Dengan kata lain, suatu tujuan (goal) yang utuh, didekomposisi atau dipecahkan kedalam unsur-unsur penyusunnya. Apabila unsur tersebut merupakan kriteria yang dipilih seyogyanya mencakup semua aspek penting terkait dengan tujuan yang ingin dicapai. Namun kita harus tetap mempertimbangkan agar kriteria yang dipulih benar-benar mempunyai makna bagi pengambilan keputusan dan tidak mempunyai makna atau pengertian yang sama, sehingga walaupun kriteria pilihan hanya sedikit namun mempunyai makna yang besar terhadap tujuan yang ingin dicapai. Setelah kriteria ditetapkan, selanjutnya adalah menentukan alternatif atau pilihan penyelesaian masalah. Secara skematik, sebagaimana terlihat pada Gambar 2.1.

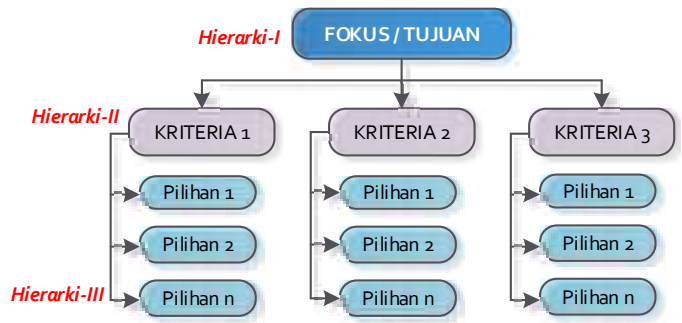

Gambar 2.1. Hierarki Permasalahan

\section{b. Penilaian / Pembandingan Elemen}

Apabila proses dekomposisi telah selesai dan hirarki telah tersusun dengan baik. Selanjutnya dilakukan penilaian perbandingan berpasangan (pembobotan) pada tiap-tiap hirarki berdasarkan tingkat kepentingan relatifnya. Pada contoh di atas, maka perbandingan dilakukan pada Hirarki III (antara alternatif), dan pada Hirarki II (antara kriteria). Penilaian atau pembobotan pada Hirarki III, dimaksudkan untuk membandingkan nilai atau karakter pilihan berdasarkan tiap kriteria yang ada. Misalnya antara pilihan 1 dan pilihan 2, pada kriteria 1 , lebih penting pilihan 1 , selanjutnya antara pilihan 1 dan pilihan 3 , lebih penting pilihan 3 dan seterusnya hingga semua pilihan akan dibandingkan satu-persatu (secara berpasangan). Hasil dari penilaian adalah nilai/bobot yang merupakan karakter dari masingmasing alternatif.

Penilaian atau pembobotan pada Hierarki II, dimaksudkan untuk membandingkan nilai pada masing-masing kriteria guna mencapai tujuan. Sehingga nantinya akan diperoleh pembobotan tingkat kepentingan masing-masing kriteria untuk mencapai tujuan yang telah ditetapkan.

Prosedur penilaian perbandingan berpasangan dalam AHP, mengacu pada skor penilaian yang telah dikembangkan oleh Thomas L Saaty, sebagai berikut:

\begin{tabular}{|c|l|}
\hline $\begin{array}{c}\text { Intensitas } \\
\text { pentingnya }\end{array}$ & \multicolumn{1}{|c|}{ Defenisi } \\
\hline 1 & $\begin{array}{l}\text { Kedua elemen / alternatif sama } \\
\text { pentingnya ( equal) }\end{array}$ \\
\hline 3 & $\begin{array}{l}\text { Elemen A sedikit lebih esensial dari } \\
\text { elemen B ( moderate) }\end{array}$ \\
\hline 5 & $\begin{array}{l}\text { Elemen A lebih esensial dari elemen B } \\
\text { (strong) }\end{array}$ \\
\hline 7 & $\begin{array}{l}\text { Elemen A jelas lebih esensial dari } \\
\text { elemen B ( very strong) }\end{array}$ \\
\hline 9 & $\begin{array}{l}\text { Elemen A mutlak lebih esensial dari } \\
\text { elemen B (very strong) }\end{array}$ \\
\hline $2,4,6,8$ & $\begin{array}{l}\text { Nilai-nilai antara di antara dua } \\
\text { perimbangan yang berdekatan }\end{array}$ \\
\hline
\end{tabular}

Dalam pembobotan tingkat kepentingan atau penilaian perbandingan berpasangan ini berlaku hukum aksioma reciprocal, artinya apabila suatu elemen A dinilai lebih esensial (5) dibandingkan dengan elemen $\mathrm{B}$, maka $\mathrm{B}$ lebih esensial 1/5 dibandingakan dengan elemen A. Apabila elemen A sama pentingnya dengan $\mathrm{B}$ maka masing-masing bernilai $=1$.

Dalam pengambilan data, misalnya dengan menggunakan kuisioner, prosedur perbandingan berganda dapat dilakukan dengan menggunakan kuisioner berupa matriks atau semantik difrensial.

Contoh Kuisioner matriks:

\begin{tabular}{|c|c|c|c|c|}
\hline $\begin{array}{c}\text { Kriteria / } \\
\text { Alternatif }\end{array}$ & $\mathbf{1}$ & $\mathbf{2}$ & $\mathbf{3}$ & $\mathbf{n}$ \\
\hline $\mathbf{1}$ & & $\ldots / \ldots$ & $\ldots / \ldots$ & $\ldots / \ldots$ \\
\hline $\mathbf{2}$ & & & $\ldots / \ldots$ & $\ldots / \ldots$ \\
\hline $\mathbf{3}$ & & & & $\ldots / \ldots$ \\
\hline $\mathbf{n}$ & & & & \\
\hline
\end{tabular}

Banyaknya sell yang harus diisi adalah $n(n-1) / 2$ karena matriks reciprocal elemen diagonalnya bernilai $=1$, jadi tidak perlu disi. Pada contoh di atas $4(4-1) / 2=6$, jadi bagian yang putih saja yang diisi. 
Pada jenis kuisioner ini, kecendrungan pembibitan dilingkari/silang berdasarkan bobot nya, jika sisi kiri lebih penting dari sisi kanan maka angka yang dilingkari adalah 9-1 pada ruas kiri dan sebaliknya.

\section{c. Penyusunan Matriks dan Uji Konsistensi}

Apabila proses pembobotan atau "pengisian kuisioner" telah selesai, langkah selanjutnya dalah penyusunan matriks berpasangan untuk melakukan normalisasi bobot tingkat kepentingan pada tiap-tiap elemen pada hirarkinya masing-masing. Pada tahapan ini analisis dapat dilakukan secara manual ataupun dengan menggunakan program komputer. Nilai-nilai yang diperoleh selanjutnya disusun kedalam matriks berpasangan serupa dengan matriks yang digunakan pada kuisioner matriks diatas. Hanya saja pada penyusunan matriks untuk analisis data ini, semua kotak harus diisi.

Langkah pertama: adalah menyatukan pendapat dari beberapa kuisioner, jika kuisioner diisi oleh pakar, maka kita akan menyatukan pendapat para pakar kedangan menggunakan persamaan rata-rata geometri:

$$
\begin{aligned}
& G=\sqrt[n]{\left(X_{1}\right)\left(X_{2}\right) \ldots\left(X_{n}\right)} \\
& \text { Dimana : } \mathrm{GM}=\text { Geometric Mean } \\
& \mathrm{X}_{1}=\text { Pakar ke-1 } \\
& \mathrm{X}_{2}=\text { Pakar ke-2 } \\
& X_{n}=\text { Pakar ke-n }
\end{aligned}
$$

Langkah kedua: menyusun matriks perbandingan, sebagai berikut:

\begin{tabular}{|c|c|c|c|c|}
\hline $\begin{array}{c}\text { Kriteria / } \\
\text { Alternatif }\end{array}$ & $\mathbf{1}$ & $\mathbf{2}$ & $\mathbf{3}$ & $\mathbf{n}$ \\
\hline $\mathbf{1}$ & 1 & $\mathrm{GM}_{12}$ & $\mathrm{GM}_{13}$ & $\mathrm{GM}_{1 \mathrm{n}}$ \\
\hline $\mathbf{2}$ & $\mathrm{GM}_{21}$ & 1 & $\mathrm{GM}_{23}$ & $\mathrm{GM}_{2 \mathrm{n}}$ \\
\hline $\mathbf{3}$ & $\mathrm{GM}_{31}$ & $\mathrm{GM}_{32}$ & 1 & $\mathrm{GM}_{3 \mathrm{n}}$ \\
\hline $\mathbf{n}$ & $\mathrm{GM}_{\mathrm{n} 1}$ & $\mathrm{GM}_{\mathrm{n} 2}$ & $\mathrm{GM}_{\mathrm{n} 3}$ & 1 \\
\hline
\end{tabular}

Sebelum melangkah lebh jauh ketahapan iterasi untuk penetapan prioritas pada pilihan alternatif atau penetapan tingkat kepentingan kriteria, maka sebelumnya dilakukan terlebih dahulu uji konsistensi. Uji konsistensi dilakukan pada masing kuisioner/pakar yang menilai atau memberikan pembobotan. Kuisioner atau pakar yang tidak memenuhi syarat konsisten dapat dianulir atau dipending untuk perbaikan. Prinsip dasar pada uji konsistensi ini adalah apabila A lebih penting dari B, kemudian $\mathrm{B}$ lebih penting dari $\mathrm{C}$, maka tidak mungkin $\mathrm{C}$ lebih penting dari $\mathrm{A}$. Tolak ukur yang digunakan adalah CI (Consistency Index) berbanding RI (Ratio Index) atau CR (Consistency Ratio).

Ratio Indeks (RI) yang umum digunakan untuk setiap ordo matriks adalah sebagai berikut:

\begin{tabular}{|c|c|c|c|c|c|c|c|c|c|c|}
\hline $\begin{array}{c}\text { Urutan } \\
\text { Matriks }\end{array}$ & $\mathbf{1}$ & $\mathbf{2}$ & $\mathbf{3}$ & $\mathbf{4}$ & $\mathbf{5}$ & $\mathbf{6}$ & $\mathbf{7}$ & $\mathbf{8}$ & $\mathbf{9}$ & $\mathbf{1 0}$ \\
\hline $\mathrm{RI}$ & 0,00 & 0,00 & 0,58 & 0,90 & 1,12 & 1,24 & 1,32 & 1,41 & 1,45 & 1,49 \\
\hline
\end{tabular}

Langkah ketiga: uji konsistensi terlebih dahulu dilakukan dengan menyusun tingkat kepentingan relatif pada masing- masing kriteria atau alternatif yang dinyatakan sebagai bobot relatif ternormalisasi (normalized relative weight). Bobot relatif yang dinormalkan ini merupakan suatu bobot nilai relatif untuk masing-masing elemen pada setiap

\begin{tabular}{|c|c|c|c|c|}
\hline Kriteria / Alternatif & 1 & 2 & 3 & $\mathbf{n}$ \\
\hline 1 & $\underset{\mathrm{n} 1}{1 / \mathrm{GM}_{11-}}$ & $\begin{array}{l}\mathrm{GM}_{12} / \\
\mathrm{GM}_{12-\mathrm{n} 2}\end{array}$ & $\begin{array}{c}\mathrm{GM}_{13} / \\
\mathrm{GM}_{13-\mathrm{n} 3}\end{array}$ & $\begin{array}{l}\mathrm{GM}_{1 \mathrm{n}} / \\
\mathrm{GM}_{13-\mathrm{n} 3}\end{array}$ \\
\hline 2 & $\begin{array}{c}\mathrm{GM}_{21} / \\
\mathrm{GM}_{11-\mathrm{n} 1}\end{array}$ & $\begin{array}{c}1 / \mathrm{GM}_{12-} \\
\mathrm{n} 2\end{array}$ & $\begin{array}{c}\mathrm{GM}_{23} / \\
\mathrm{GM}_{13-\mathrm{n} 3}\end{array}$ & $\begin{array}{c}\mathrm{GM}_{2 \mathrm{n}} / \\
\mathrm{GM}_{13-\mathrm{n} 3}\end{array}$ \\
\hline 3 & $\begin{array}{c}\mathrm{GM}_{31} / \\
\mathrm{GM}_{11-\mathrm{n} 1}\end{array}$ & $\begin{array}{c}\mathrm{GM}_{32} / \\
\mathrm{GM}_{12-\mathrm{n} 2}\end{array}$ & 1/ $\mathrm{GM}_{13-\mathrm{n} 3}$ & $\begin{array}{l}\mathrm{GM}_{3 \mathrm{n}} / \\
\mathrm{GM}_{13-\mathrm{n} 3}\end{array}$ \\
\hline $\mathbf{n}$ & $\begin{array}{c}\mathrm{GM}_{\mathrm{n} 1} / \\
\mathrm{GM}_{11-\mathrm{n} 1}\end{array}$ & $\begin{array}{c}\mathrm{GM}_{\mathrm{n} 2} / \\
\mathrm{GM}_{12-\mathrm{n} 2}\end{array}$ & $\begin{array}{c}\mathrm{GM}_{\mathrm{n} 3} / \\
\mathrm{GM}_{13-\mathrm{n} 3}\end{array}$ & $\begin{array}{c}1 / \mathrm{GM}_{13-} \\
\mathrm{n} 3\end{array}$ \\
\hline
\end{tabular}
kolom yang dibandingkan dengan jumlah masing-masing elemen:

\begin{tabular}{|c|c|c|c|c|}
\hline $\begin{array}{c}\text { Kriteria / } \\
\text { Alternatif }\end{array}$ & $\mathbf{1}$ & $\mathbf{2}$ & $\mathbf{3}$ & $\mathbf{n}$ \\
\hline $\mathbf{1}$ & 1 & $\mathrm{GM}_{12}$ & $\mathrm{GM}_{13}$ & $\mathrm{GM}_{1 \mathrm{n}}$ \\
\hline $\mathbf{2}$ & $\mathrm{GM}_{21}$ & 1 & $\mathrm{GM}_{23}$ & $\mathrm{GM}_{2 \mathrm{n}}$ \\
\hline $\mathbf{3}$ & $\mathrm{GM}_{31}$ & $\mathrm{GM}_{32}$ & 1 & $\mathrm{GM}_{3 \mathrm{n}}$ \\
\hline $\mathbf{n}$ & $\mathrm{GM}_{\mathrm{n} 1}$ & $\mathrm{GM}_{\mathrm{n} 2}$ & $\mathrm{GM}_{\mathrm{n} 3}$ & 1 \\
\hline$\sum$ & $\mathrm{GM}_{11-\mathrm{n} 1}$ & $\mathrm{GM}_{12-\mathrm{n} 2}$ & $\mathrm{GM}_{13-\mathrm{n} 3}$ & $\mathrm{GM}_{1 \mathrm{n}-\mathrm{ni}}$ \\
\hline
\end{tabular}

Maka bobot relatif ternormalisasi adalah:

Selanjutnya dapat dihitung Eigen faktor hasil normalisasi dengan merata-ratakan penjumlahan tiap baris pada matriks di atas.

\begin{tabular}{|c|c|c|c|c|c|}
\hline $\begin{array}{c}\text { Kriteria / } \\
\text { Alternatif }\end{array}$ & $\mathbf{1}$ & $\mathbf{2}$ & $\mathbf{3}$ & $\mathbf{n}$ & $\begin{array}{c}\text { Eigen } \\
\text { Faktor } \\
\text { Utama }\end{array}$ \\
\hline $\mathbf{1}$ & $\begin{array}{c}1 / \mathrm{GM}_{11-} \\
\mathrm{n} 1\end{array}$ & $\begin{array}{c}\mathrm{GM}_{12} / \\
\mathrm{GM}_{12-\mathrm{n} 2}\end{array}$ & $\begin{array}{c}\mathrm{GM}_{13} / \\
\mathrm{GM}_{13-\mathrm{n} 3}\end{array}$ & $\begin{array}{c}\mathrm{GM}_{1 \mathrm{n}} / \\
\mathrm{GM}_{13-\mathrm{n} 3}\end{array}$ & $\begin{array}{c}\text { Rerata } \\
\text { row } 1 / 4 \\
\left(\bar{X}_{1}\right)\end{array}$ \\
\hline $\mathbf{2}$ & $\begin{array}{c}\mathrm{GM}_{21} / \\
\mathrm{GM}_{11-\mathrm{n} 1}\end{array}$ & $\begin{array}{c}1 / \mathrm{GM}_{12-} \\
\mathrm{n} 2\end{array}$ & $\begin{array}{c}\mathrm{GM}_{23} / \\
\mathrm{GM}_{13-\mathrm{n} 3}\end{array}$ & $\begin{array}{c}\mathrm{GM}_{2 \mathrm{n}} / \\
\mathrm{GM}_{13-\mathrm{n} 3}\end{array}$ & $\begin{array}{c}\text { Rerata } \\
\text { row } 2 / 4 \\
\left(\bar{X}_{\bar{z}}\right)\end{array}$ \\
\hline $\mathbf{3}$ & $\begin{array}{c}\mathrm{GM}_{31} / \\
\mathrm{GM}_{11-\mathrm{n} 1}\end{array}$ & $\begin{array}{c}\mathrm{GM}_{32} / \\
\mathrm{GM}_{12-\mathrm{n} 2}\end{array}$ & $\begin{array}{c}1 / \mathrm{GM}_{13-} \\
\mathrm{n} 3\end{array}$ & $\begin{array}{c}\mathrm{GM}_{3 \mathrm{n}} / \\
\mathrm{GM}_{13-\mathrm{n} 3}\end{array}$ & $\begin{array}{c}\text { Rerata } \\
\text { row } 3 / 4 \\
\left(\bar{X}_{-5}\right)\end{array}$ \\
\hline $\mathbf{n}$ & $\begin{array}{c}\mathrm{GM}_{\mathrm{n} 1} / \\
\mathrm{GM}_{11-\mathrm{n} 1}\end{array}$ & $\begin{array}{c}\mathrm{GM}_{\mathrm{n} 2} / \\
\mathrm{GM}_{12-\mathrm{n} 2}\end{array}$ & $\begin{array}{c}\mathrm{GM}_{\mathrm{n} 3} / \\
\mathrm{GM}_{13-\mathrm{n} 3}\end{array}$ & $\begin{array}{c}1 / \\
\mathrm{GM}_{13-\mathrm{n} 3}\end{array}$ & $\begin{array}{c}\text { Rerata } \\
\text { row n/4 } \\
\left(\bar{X}_{n}\right)\end{array}$ \\
\hline
\end{tabular}

Selanjutnya tentukan nilai CI (Consistency Index) dengan persamaan:

$$
C=\frac{d m \quad-1}{n-1}
$$

dimana $C I$ adalah indeks konsistensi dan Lambda maksimum adalah nilai eigen terbesar dari matriks berordo n.

Nilai eigen terbesar adalah jumlah hasil kali perkalian jumlah kolom dengan eigen vaktor utaman. Sehingga dapat diperoleh dengan persamaan:

$\lambda=\left(\sum_{1-\overline{1}} \times \bar{X} 1\right)+\cdots+\left(\sum_{L_{1-1}} \times \bar{X} n\right) \ldots \ldots .(2.3)$ Setelah memperoleh nilai lambda maksismum selanjutnya dapat ditentukan nilai CI. Apabila nilai CI bernilai nol (0) berarti matriks konsisten. Jika nilai CI yag diperoleh lebih besar dari 0 (CI > 0) selanjutnya diuji batas ketidak konsistenan yang diterapkan oleh Saaty. Pengujian diukur dengan menggunakan Consistency Ratio (CR), yaitu nilai indeks, atau perbandingan antara CI dan RI:

$$
C=\frac{C}{R} \text {. }
$$

Nilai RI yang digunakan sesuai denan ordo n matriks. Apabila CR matriks lebih kecil $10 \%(0,1)$ berarti bahwa ketidak konsistenan pendapat masing dianggap dapat diterima. 


\section{d. Penarikan Kesimpulan}

Penarikan kesimpulan dilakukan dengan mengakumulasi nilai/ bobot global yang merupakan nilai sensitivitas masing-masing elemen. Seperti pada contoh diatas, maka kesimpulan utamanya adalah aspek kekuatan perlu diperhatikan karena merupakan prioritas utama, kemudian aspek kelemahan, ancaman dan peluang.

\section{HASIL DAN PEMBAHASAN}

\subsection{Methode AHP.}

Kuesioner dibagikan secara terpisah kepada responden yang memiliki pendidikan dan berpengalaman dalam bidang pengoperasian kapal. Disamping itu juga kepada akademisi yang mampu untuk memberikan penilaian sesuai bidang kajian ini. Setelah dilakukan analisis, diperoleh hasil sebagai berikut :

\subsubsection{Hierarki Pengambilan Keputusan}

Hierarki pengambilan keputusan sebagaimana terlihat pada gambar berikut, dimana tujuan pemilihan alat angkut Bahan Bakar Minyak untuk wilayah kepulauan memiliki beberapa kriteria sebagai bahan pertimbangan dalam proses pengambilan keputusan. Kriteria yang ditetapkan didasarkan pada kondisi pengoperasian kapal, kondisi wilayah perairan dan juga aspek ekonomi dan teknis dalam pengoperasian kapal.

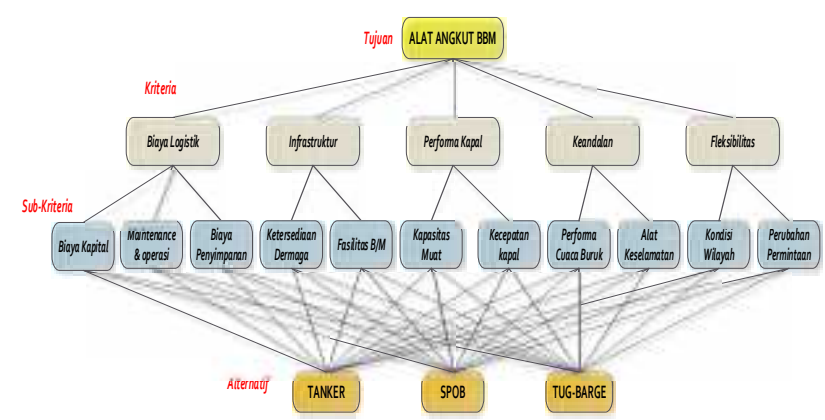

Gambar 3.1. Hierarki Pengambilan Keputusan

Comparative judgment merupakan proses perbandingan antara dua elemen (pairwise comparation) dalam suatu level sehubungan dengan level di atasnya. Prinsip comparative judgment memungkinkan untuk menyelesaikan perbandingan berpasangan dari seluruh kombinasi elemen-elemen dalam sebuah kluster dengan memperhatikan tujuan utama atau goal dari kluster. Perbandingan berpasangan digunakan untuk memperoleh local priorities atau bobot dari elemen-elemen dalam sebuah kluster dengan memperhatikan goal. Matriks ini mencerminkan tingkat kepentingan relative antara dua elemen, yang diukur dengan skala yang kita pakai. Penentuan tingkat kepentingan pada setiap hirarki atas pendapat dilakukan dengan teknik komparasi berpasangan (pairwise comparison). Teknik komparasi berpasangan yang digunakan dalam AHP dilakukan dengan cara membandingkan antara elemen satu dengan elemen yang lainnya dalam satu tingkat hirarki secara berpasangan sehingga diperoleh nilai kepentingan dari masingmasing elemen. Penilaian dilakukan dengan memberikan bobot numeric pada setiap elemen yang dibandingkan dengan hasil wawancara langsung dengan responden. Responden bisa seorang ahli atau bukan, tetapi terlibat dan mengetahui permasalahan tersebut.

Pembentukan pairwise comparison menjadi suatu tahapan yang penting dalam proses AHP, karena penghitungan pembobotan hanya dimungkinkan apabila matriks perbandingannya konsisten atau mendekati konsisten. Oleh karena pembentukan pairwise comparison penting, maka pemakaian skala untuk pembobotan juga harus diperhatikan. Skala pembobotan yang baik, akan menjadikan hasil pembentukan pairwise comparison lebih mencerminkan kondisi sebenarnya, sehingga hasil pembobotan akan lebih akurat.

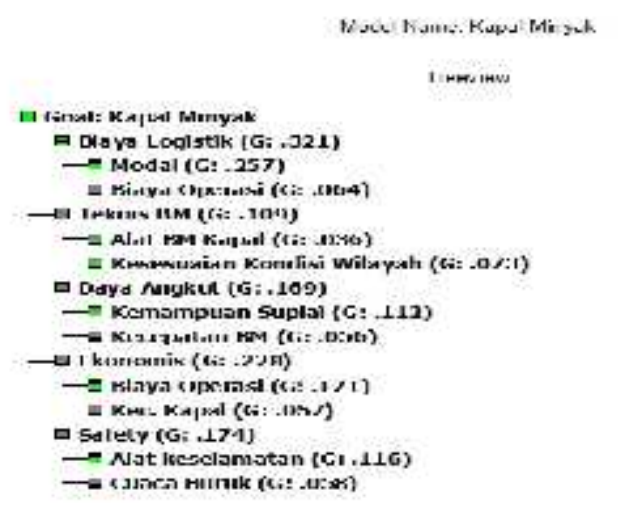

Gamba 3.2. Susunan Sub Kriteria

\subsubsection{Pembobotan Kriteria}

Sebagaimana prosedur yang dilakukan pada analisis manual, tahap pembobotan pertama dilakukan pada hierarki II terhadap hierarki I. Pada analisis manual sebelumnya diketahui bahwa hasil pembobotan adalah sebagai berikut:

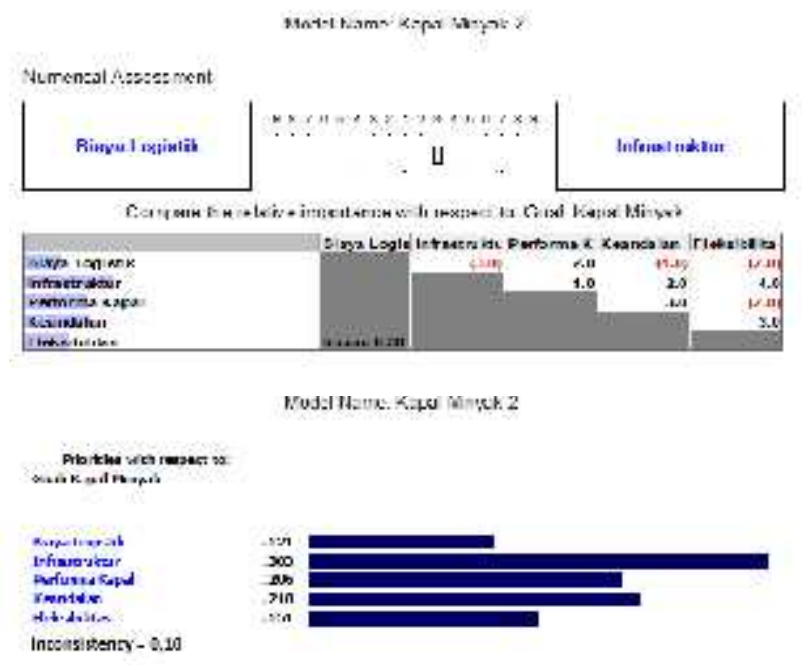

Gambar 3.3. Pembobotan Kriteria 
Nahh, nilai-nilai hasil pembobotan ini akan dimasukkan kedalam program Expert Choice.

Selanjutnya akan muncul window compare the relative preference with respect to: Goal: Pada kotak tersebut terdapat tombol radio (radio button) yang dapat anda geser kekanan atau kekiri sesuai dengan peringkat bobot yang diberikan. Contoh Perbandingan antara Biaya Logistik dan Infrastrukutr. Hasil pembobotan pada Gambar 3.3. diatas menunjukkan bahwa nilai infrastruktur 3 (tiga) kali lebih penting dibandingkan dengan biaya logistik. Selanjut lakukan pengisian untuk kolomkolom lain sebagaimana prosedur tersebut hingga diperoleh hasil (Gambar 3.3). Kelebihan analisis menggunakan Expert Choice ini adalah informasi tentang konsistensi penilaian dapat langsung diketahui Konsistensi pembobotan pada hierarki kedua ini menunjukkan angka 0,05 atau $<0,1$ sehingga hasil penilaian dianggap memenuhi persyaratak inkonsistensi atau pembobotan dilakukan secara konsisten.

\subsubsection{Pembobotan Alternatif}

Pembobotan kedua dilakukan pada masingmasing alternaitf terhadap kriteria (hierarki II). Pembobotan dimaksudkan untuk memberi penilaian karakter masing-masing alat angkut (alternatif) berdasarkan kriteria yang ada. Langkah ini akan menghasilkan nilai-nilai masing-masing bobot berdasarkan hasil penilaian yang diperoleh pada analisis secara manual. Pertama bandingkan antara masing-masing alternatif alat angkut dengan jenis lainnya hal kriteria tertentu. Misalkan Tanker dan Tug-Barge untuk kriteria Biaya Logistik.

\subsubsection{Sintesis}

Setelah semua pembobotan alternatif dilakukan untuk semua kriteria, selanjutnya perolehan hasil sintesis sebagaimana terlihat secara grafis pada Gambar 3.4. dimana Tug Barge memiliki prioritas yang tinggi. Dengan demikian dapat disimpulkan bahwa Tug Barge sebagai jenis alat angkut BBM yang akan dikembangkan di wilayah kepulauan. Hasil analisis yang dilakukan secara manual menunjukkan tingkatan prioritas yang sama, namun terdapat selisih nilai sistensis sekitar 0,015 sampai 0,02 .

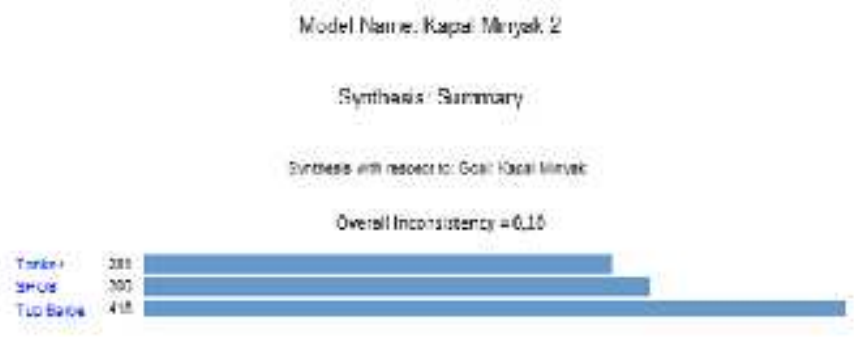

Gambar 3.4. Hasil Sintesis

\section{KESIMPULAN}

Beberapa hal yang dapat disimpulkan dari penelitian ini adalah :

- Jumlah penduduk yang relatif sedikit dengan tingkat pertumbuhan ekonomi yang relatif lambat, berpengaruh pada permintaan bahan bakar minyak yang juga relatif kecil / sedikit, dengan jangkauan pelayanan yang cukup jauh.

- Kondisi wilayah pulau-pulau yang minim infrastruktur dan tantangan alam yang berat ( gelombang \& angin ) membutuhkan pemilihan jenis alat angkut yang sesuai untuk menjamin kelancaran proses distribusi.

- Tug-Barge sebagai salah satu jenis alat angkut perlu untuk dikembangkan mengingat dari sistim pengoperasian lebih murah dibandingkan dengan jenis yang lain. Disamping itu dari sisi teknis operasi Tug-Barge lebih sesuai untuk wilayah pulau terpencil dengan demand yang rendah.

- Dengan pola operasi yang menempatkan barge sebagai wadah muatan bahan bakar minyak, akan memungkinkan pengembangan untuk menjadikan barge sebagai tangki timbun/cadangan stok di pulau untuk kondisi darurat.

\section{DAFTAR PUSTAKA}

Agostinho Agra, Marielle Christiansen, Cs, [2015], “ A Maritime Inventory Routing Problem with Stochastic Sailing and Port Times". Elsevier, Computers \& Operations Research.

Chaug-Ing Hsu, Yu-Ping Hsieh [2007] " Routing, Ship size, and Sailing Frequency Decision-making for a Maritime Hub-and-spoke Container Network “ Mathematical and Computer Modelling 45 (2007) 899-916.

David Bredstrom, Kjetil Haugen, Asmund Olstad, Jan Novotnyc, [ 2015 ], "A Mixed Integer Linear Programming Model Applied In Barge Planning For Omya " Elsevier , Operations Research Perspectives 2 (20150, 150-155

Jean-Paul Rodrique, cs, [2006]. “ The Geography of Transport Systems “ Roudledge Taylor and Francis Group, London and New York.

John J. Coyle, Edward J. Bardi, C. John Langley Jr. [ 1996 ], "The Management of Business Logistic" Sixth edition, West Publising Company, New York

Kris Braekers, An Caris, Gerrit K. Janssens, [2013], "Optimal Shipping Routes And Vessel Size For Intermodal Barge Transport With Empty Container Repositioning “, Elsevier, Computers In Industry 64 (2013) 155-164

Laurent Alfandari, Tatjana Davidovi, Fabio Furini, Ivana Ljubi, Vladislav Marasd, Sebastien Martin, 
[2017], "Tighter MIP Models for Barge Container Ship Routing “, Elsevier, Omega (2017) 1-17.

Lu Zhen, Kai Wang, Shuaian Wang, Xiaobo Qu, [2018], "Tug Scheduling For Hinterland Barge Transport: A Branch-And-Price Approach“ European Journal Of Operational Research 265 (2018) 119-132

Stefano Fazi, Jan C. Fransoo, Tom Van Woensel, [2015], “A Decision Support System Tool For The Transportation By Barge Of Import Containers: A Case Study "Elsevier, Decision Support Systems 79 (2015) 33-45

Yunfei WANG, Ioana C. Bilegan, Teodor Gabriel Crainic, Abdelhakim Artiba , [2014], "Performance Indicators For Planning Intermodal Barge Transportation Systems " Elsevier,Transportation Research Procedia 3 (2014) $621-630$

A.K. Kar, [2009], : “Modeling Of Supplier Selection In E-Procurement As A Multi-Criteria Decision Making Problem “, Sprouts: Working papers in Information Systems 9 (40) (2009) 1-22.

L. Junior, F. Rodrigues, O. Lauro, R. Carpinetti, L. Cesar, [2014], : "A Comparison Between Fuzzy AHP And Fuzzy TOPSIS Methods To Supplier Selection “, , Applied Soft Computing 21 (2014) 194-209.

M.M. Köksalan, J. Wallenius, S. Zionts, [2011], Multiple Criteria Decision Making: From Early History To The 21st Century, World Scientific, 2011

C. Kahraman, S. C. Onar, B. Oztaysi, [2015] : Fuzzy Multicriteria Decision-Making: A Literature Review, International Journal of Computational Intelligence Systems 8(4) (2015) 637-666.
E.K. Zavadskas, Z. Turskis, [2011], : Multiple Criteria Decision Making (MCDM) Methods In Economics : An overview, Technological and Economic Development of Economy 17(2) (2011) $397-427$.

E.K. Zavadskas, Z. Turskis, S. Kildien , [2014], : "State Of Art Surveys Of Overviews On MCDM/MADM Methods ", Technological and Economic Development of Economy 20 (1) 165179.

T.L. Saaty, [1980], : The Analytic Hierarchy Process: Planning, Priority Setting, Resources Allocation, McGraw-Hill, New York, 1980.

E.K. Zavadskas, Z. Turskis, [2010], : A New Additive Ratio Assessment (ARAS) Method In Multicriteria Decision-Making, Technological and Economic Development of Economy 16 (2) (2010) 159-172.

Z. Turskis, E.K. Zavadskas, V. Kutut, [2013], : A Model Based On ARAS-G And AHP Methods For Multiple Criteria Prioritizing Of Heritage Value, International Journal of Information Technology \& Decision Making 12(1) (2013) 45-73.

W.K.M. Brauers, E.K. Zavadskas, [2006],: "The MOORA Method And Its Application To Privatization In A Transition Economy", Control and Cybernetics 35(2) 445-469.

A. Krylovas, E.K. Zavadskas, N. Kosareva, S. Dadelo, [2014], : "New KEMIRA method for determining criteria priority and weights in solving MCDM Problem " , International Journal of Information Technology \& Decision Making 13(6) (2014) 1119-1133. 